Article

\title{
Predicting the Presence of Leptospires in Rodents from Environmental Indicators Opens Up Opportunities for Environmental Monitoring of Human Leptospirosis
}

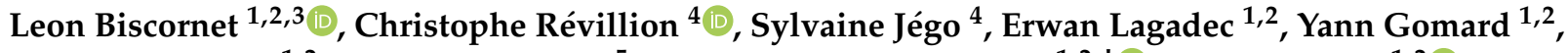 \\ Gildas Le Minter ${ }^{1,2}$, Gérard Rocamora ${ }^{5}$, Vanina Guernier-Cambert ${ }^{1,2,+} \mathbb{C}^{\mathbb{B}}$, Julien Mélade ${ }^{1,2}(\mathbb{D}$, \\ Koussay Dellagi ${ }^{1,2, \ddagger}$, Pablo Tortosa ${ }^{1,2}$ (i) and Vincent Herbreteau ${ }^{4, *}$ (])
}

check for updates

Citation: Biscornet, L.; Révillion, C.; Jégo, S.; Lagadec, E.; Gomard, Y.; Le Minter, G.; Rocamora, G.;

Guernier-Cambert, V.; Mélade, J.; Dellagi, K.; et al. Predicting the Presence of Leptospires in Rodents from Environmental Indicators Opens Up Opportunities for Environmental Monitoring of Human Leptospirosis. Remote Sens. 2021, 13, 325. https://doi.org/10.3390/rs13020325

Received: 15 October 2020

Accepted: 8 January 2021

Published: 19 January 2021

Publisher's Note: MDPI stays neutral with regard to jurisdictional claims in published maps and institutional affiliations.

Copyright: (c) 2021 by the authors. Licensee MDPI, Basel, Switzerland. This article is an open access article distributed under the terms and conditions of the Creative Commons Attribution (CC BY) license (https:// creativecommons.org/licenses/by/ $4.0 /)$.
1 UMR PIMIT (Processus Infectieux en Milieu Insulaire Tropical), Université de La Réunion, CNRS 9192 INSERM U 1187, IRD 249, Plateforme de Recherche CYROI, 97490 Sainte Clotilde, La Réunion, France; leon.biscornet@gmail.com (L.B.); erwan.lagadec69@yahoo.fr (E.L.); yann.gomard@ird.fr (Y.G.); leminterbzh@yahoo.fr (G.L.M.); vanina.guernier@gmail.com (V.G.-C.); julien.melade@hotmail.fr (J.M.); koussay.dellagi@pasteur.fr (K.D.); pablo.tortosa@univ-reunion.fr (P.T.)

2 Centre de Recherche et de Veille sur les Maladies Emergentes dans l'Océan Indien (CRVOI), Plateforme de Recherche CYROI, 97490 Sainte Clotilde, La Réunion, France

3 Seychelles Public Health Laboratory, Infectious Disease Surveillance Unit, Public Health Authority, Ministry of Health, Mont Fleuri P.O. Box 52, Mahé, Seychelles

4 UMR ESPACE-DEV, IRD (IRD, Univ. Antilles, Univ. Guyane, Univ. Montpellier, Univ. Réunion), 97410 Saint-Pierre, La Réunion, France; christophe.revillion@univ-reunion.fr (C.R.); sylvaine.jego@ird.fr (S.J.)

5 Island Biodiversity and Conservation Centre, University of Seychelles (Unisey), Anse Royale P.O. Box 1348, Mahé, Seychelles; whiteye@seychelles.net

* Correspondence: vincent.herbreteau@ird.fr; Tel.: +855-76-208-2831

+ Current address: National Animal Disease Center, Agricultural Research Service, United States Department of Agriculture, Ames, IA 50010, USA.

$\ddagger$ Current address: Institut Pasteur (Direction Internationale), CEDEX 15, 75724 Paris, France.

\begin{abstract}
Leptospirosis, an environmental infectious disease of bacterial origin, is the infectious disease with the highest associated mortality in Seychelles. In small island territories, the occurrence of the disease is spatially heterogeneous and a better understanding of the environmental factors that contribute to the presence of the bacteria would help implement targeted control. The present study aimed at identifying the main environmental parameters correlated with animal reservoirs distribution and Leptospira infection in order to delineate habitats with highest prevalence. We used a previously published dataset produced from a large collection of rodents trapped during the dry and wet seasons in most habitats of Mahé, the main island of Seychelles. A land use/land cover analysis was realized in order to describe the various environments using SPOT- 5 images by remote sensing (object-based image analysis). At each sampling site, landscape indices were calculated and combined with other geographical parameters together with rainfall records to be used in a multivariate statistical analysis. Several environmental factors were found to be associated with the carriage of leptospires in Rattus rattus and Rattus norvegicus, namely low elevations, fragmented landscapes, the proximity of urbanized areas, an increased distance from forests and, above all, increased precipitation in the three months preceding trapping. The analysis indicated that Leptospira renal carriage could be predicted using the species identification and a description of landscape fragmentation and rainfall, with infection prevalence being positively correlated with these two environmental variables. This model may help decision makers in implementing policies affecting urban landscapes and/or in balancing conservation efforts when designing pest control strategies that should also aim at reducing human contact with Leptospira-laden rats while limiting their impact on the autochthonous fauna.
\end{abstract}

Keywords: leptospirosis; rodents; Rattus rattus; Rattus norvegicus; spatial analysis; remote sensing; landscape metrics; satellite; ecology 


\section{Introduction}

Leptospirosis is a bacterial disease caused by pathogenic spirochetes of the genus Leptospira [1,2]. Throughout the world, leptospirosis occurs mostly in tropical climates and in a variety of environments, affecting urban and rural populations [3], including on islands [4]. It has a major impact on human health with an estimation of over one million cases and about 60,000 deaths yearly worldwide [5,6]. Despite this considerable burden, leptospirosis remains a neglected disease as it affects the poorest populations, it is associated with flu-like unspecific symptoms and its diagnosis is challenging in low-income countries due to the usual unavailability of molecular diagnostic tools in these settings [6]. Over the past few years, research programs have expanded to address the burden of the disease in human populations, identify main animal reservoirs and better understand its ecology $[7,8]$. However, many countries, especially in Africa, lack information on this disease [9].

Leptospirosis usually occurs after contact with a moist environment (water or soil) containing pathogenic leptospires [10]. These bacteria can survive from a few weeks to several months under favorable environmental conditions and hence infect a number of mammalian hosts [11,12], although nonmammal hosts have also been reported $[13,14]$. Among mammalian hosts, rodents play an important role due to their presence in a variety of environments [8]. In reservoir hosts, leptospires colonize the renal tubules and are chronically shed and dispersed into the environment through urine [1]. Therefore, environmental conditions are determining factors of the transmission of these pathogens: they condition the survival time of bacteria in the environment and the presence of animal species able to act as reservoirs, which in turn contribute to the contamination of the environment. Identifying environmental factors that allow the prediction of leptospire presence in the environment and/or the carriage of leptospires in animal reservoirs can thus help identify the settings where humans are most likely to get infected.

Several studies have looked at the environmental patterns of leptospirosis epidemiology. Different risk factors have been highlighted depending on the geographic scales. At smaller geographic scales (i.e., over large areas), climate factors and habitat types are known to delineate species distribution as they mark the frontiers of their fundamental ecological niche $[15,16]$. These factors, for example, temperature range and cumulative rainfall, may in turn be related to altitude and land cover. Flooding has been shown as a major factor of bacterial dispersal and of increased human exposure [17]. In a bibliographic review, Mwachui et al. concluded that flooding and heavy rainfall were major drivers of leptospirosis incidence on islands and in Asia [8]. Additionally, in Cambodia, Ledien et al. showed that the detection of flooded areas helped to predict the risk of leptospirosis infection [18]. In New Caledonia, the El Niño Southern Oscillation (ENSO), which causes significant changes in rainfall, has been associated with outbreaks of leptospirosis and is therefore considered to contribute to the occurrence of leptospirosis [19]. Lastly, an association of leptospirosis to specific habitat types has been enlightened in some studies, as in southern Brazil (the state of Rio Grande do Sul), where the cases of leptospirosis in rural areas are restricted to specific ecoregions [20].

At a larger scale (i.e., over smaller areas), environmental characteristics, topography, meteorology, human presence and species interactions affect the presence and density of each species (as theorized for ecological niche modeling) [16]. Thus, leptospirosis may present specific patterns related to each environmental setting [8]. In the Brazilian city of Salvador, an increased exposure to leptospirosis was associated with the location of households at lower elevations [21]. In Southeast Asia, an ecological sampling of rodents in various landscapes showed that their prevalence in different species of leptospires varies with their habitats (i.e., L. borgpetersenii is highly prevalent in nonfloodable lands while $L$. interrogans and L. borgpetersenii coexist with similar prevalence in rice fields and forests) [22]. Similarly, in northern Thailand, investigation of Leptospira spp. in rodents revealed a higher prevalence of infection in animals living in forested habitats than in 
those living near villages where the prevalence of human leptospirosis is high (i.e., villages located in nonforested areas close to rivers) [23].

At such scales, these studies have demonstrated the need for and capacity of remote sensing techniques to analyze satellite imagery in order to construct environmental indicators that allow risk prediction. However, spatial and temporal resolutions of the data have an impact on the analyses. For instance, the detection of flooded areas is relatively difficult to assess by optical satellite imagery, since cloud cover is generally important during the rainy season. An alternative is to use synthetic aperture radar (SAR) satellites for the study of wetlands, which can be of great interest for health [24]. In addition, flood maps are sometimes produced on an annual time scale, which is not appropriate to capture the local temporal impact of flooding on leptospirosis. In Thailand for instance, the comparison of flood maps with leptospirosis incidence at a national scale showed an inconsistent relationship [25]. These maps are hence an impressive piece of work based on hundreds of satellite images [26] but may not be suitable to catch the local temporal impact of flooding on leptospirosis.

Therefore, the question of whether environmental indicators obtained through the analysis of satellite images allow predicting the carriage of leptospires in reservoirs, or even the occurrence of human cases, remains open. Ledien et al. paved the way by showing the potential of flood-representative vegetation indices (especially the modified normalized difference vegetation index-MNDWI, calculated from MODIS satellite images) in predicting leptospirosis seroconversion [18]. However, at the local scale, such predictions require finer data. To address this question, we looked at leptospirosis in a small area, the island of Mahé in Seychelles, where leptospirosis is a disease of major public health concern $[14,27,28]$.

Mahé is the largest and most populated island (78,896 inhabitants in 2017) in the Seychelles Archipelago, located about $1500 \mathrm{~km}$ east of Africa, in the Indian Ocean. With its highest peak at $905 \mathrm{~m}$ (Morne Seychellois), Mahé presents varied and hilly landscapes on a small territory. Several mammalian species have been introduced in Seychelles, all of which are likely to be reservoirs of leptospirosis. These are mostly introduced commensal rodents (Rattus rattus, Rattus norvegicus and Mus musculus) but also hares, rabbits, dogs, cats and tenrecs (Tenrec ecaudatus, a small mammal in the family Tenrecidae) [29]. In addition, the endemic fruit bat of the inner islands of Seychelles, Pteropus seychellensis, is a potential reservoir with an unknown Leptospira species reported in one bat from a small sampling [14,30]. Rodents are the most abundant terrestrial mammals in Seychelles. They are found in all ecosystems, and can be abundant in towns and villages, agricultural lands and wooded hills. They are notoriously important actors in the maintenance, dispersion and transmission of leptospires to humans.

This study aimed at identifying environmental factors associated with murine rodent distribution and Leptospira infection. The objective was also to see the predictive potential of such indicators, which could be used for the environmental monitoring of leptospirosis and targeted control actions.

\section{Materials and Methods}

\subsection{Sampling Permit and Ethics Approval}

Approval for the trapping and investigation of rats was received from the Seychelles Bureau of Standards (ref. A0157). The collection, handling, external examination and dissection of each animal followed the European Union legislation for the protection of animals used for scientific purposes (Directive 2010/63/EU) and the reference rodent protocols [31-33]. The research protocol's ethical terms were defined under accreditation 03387 (FEDER POCT LeptOI 32913 project) and were approved by the CYROI Institutional Animal Care and Use Committee (Comité d'Ethique du CYROI n 114, IACUC certified by the French Ministry of Higher Education and Research). 


\subsection{Animal Sampling and Leptospira Detection}

The sampling schemes have been described elsewhere [14], but one site ("Beau Vallon") was excluded because there were only three trap-nights out of the trapping protocol for the environmental analyses. Briefly, rodents were captured on Mahé Island at 11 sampling sites (Casse Dent, Chemin Dame le Roi, Grand Bois/Mont Céphale, La Gogue, Fairview La Misère, La Réserve, Police Bay, Port Launay, Providence Industrial Estate, Reclaimed Land near the airport (Zone 21), Victoria) during the dry season (southeast tradewinds) in June and July 2013, and during the wet (northwest tradewinds) monsoonal season in February and March 2014. At each site, 40 to 80 wire live-traps baited with roasted coconut were placed in line $15 \mathrm{~m}$ apart in the afternoon. The following morning, captured animals were collected and descriptive information was recorded in the field, including the GPS coordinates, a short description of the habitat and of the state of the trap. The captured animals were handled in a laboratory of the Ministry of Health. The external measurements included weight, head and body length, tail length, ear length and hind foot length. The sex and maturity (juvenile or adult status) of the animals were determined by the external and internal observation of the reproductive organs (including the breeding conditions, presence of scars or wounds, position of testis). Maturity was then cross-checked with external measurements to identify possible inconsistencies. External observation permitted initial identification of the species. In order to validate the identification of Rattus rattus with respect to $R$. norvegicus, each $R$. rattus was also sequenced at the cytochrome b (cytb) locus [14]. Blood was collected by cardiac puncture and kidneys were removed and stored in liquid nitrogen for investigation of Leptospira spp. Fresh kidney tissue were also inoculated to culture medium [14]. The infection status of rodents, determined through RT-qPCR or culture on the kidney samples was used as a variable in the construction of the models. The trapping rate was calculated for a given species by dividing the number of animals caught by the total number of traps that caught a rat or remained opened (excluding those traps that caught other species).

\subsection{Landscape Analysis}

In view of the relatively small size of Mahé Island and the diversity of rodent habitats, this study required a precise and recent land use/land cover dataset, which was not available. The SEAS-OI Station (http:/ / www.seas-oi.org/) provided us with two scenes of high-resolution and near cloud-free SPOT-5 satellite images (@ CNES-2013, Distribution Astrium services/Spot images S.A., France, all rights reserved). Each scene is composed of a panchromatic image at $2.5 \mathrm{~m}$ spatial resolution and a multispectral image at $10 \mathrm{~m}$. They were acquired on 6 December 2012 and 6 January 2013. We preprocessed the raw images (level 1A) with the open source software OrfeoToolBox 5.8.0 (OTB, https:/ / www.orfeotoolbox.org /) in order to make the images comparable. In a first step, we orthorectified the images with the orthorectification functionality using the Shuttle Radar Topography Mission digital elevation model (SRTM DEM) at $90 \mathrm{~m}$ resolution (http://dwtkns.com/ $\mathrm{srtm} /$ ). We then converted the data to top-of-atmosphere (TOA) reflectance using the OpticalCalibration tool. Finally, we merged the panchromatic and multispectral pairs with the BundleToPerfectSensor function to produce a multispectral image with the spatial resolution of the panchromatic image. We applied and adapted the classification process to each of the two merged images.

We realized an object-based image analysis (OBIA) with eCognition software (eCognition Developer 9.0.3, (c) 2014 Trimble Germany GmbH, Munich, Germany) as already described [34,35]. The OBIA process involves a segmentation of the image pixels into objects and a classification of these objects according to intrinsic (reflectance, shape, texture), topologic (relations to neighboring objects) and contextual properties (semantic relationships between objects). We chose the land use/land cover classes among the first level of the nomenclature used by the United States Geological Survey [36], further adapting it to the tropical environment of Mahé. The Seychelles Ministry of Habitat, Infrastructure and Land Transport provided complementary geographical vector data, 
which helped improve this classification, in particular to differentiate between urban and peri-urban areas. We organized a field observation campaign in January 2014 to measure the quality of the land use/land cover classification. We used the Locus Map application (https:/ / www.locusmap.eu/) for mobile devices, which allowed us to record georeferenced field observations and display the satellite images acquired for the study. We recorded more than 30 observations for each class of land use/land cover, throughout the island. We built a confusion matrix to verify whether the classes observed in the field were correctly identified on the satellite images [37].

We then used this land use/land cover classification to compute landscape indices around the locations of each captured animal [38]. These indices included the minimum distance between each animal and each land use class. They also included the percentage area of each class in buffer zones of different sizes $(100,500$ and $1000 \mathrm{~m})$ in order to take into account potential distances traveled by animals. In each of these buffer zones, we calculated an index of landscape fragmentation, called edge density and obtained by dividing the total length of the contour of each land use patch (i.e., polygons) within each buffer by the buffer area. A higher edge density is associated with a more fragmented landscape. Lastly, we estimated the ground elevation and slope by using the SRTM (Shuttle Radar Topography Mission, http://srtm.usgs.gov/) digital elevation model (DEM) at a $90 \mathrm{~m}$ spatial resolution.

\subsection{Meteorological Data}

The Seychelles Meteorological Authority provided monthly rainfall data measured at 14 ground stations throughout Mahé Island. We spatially interpolated these data using an inverse distance weighting method with ArcGIS software. We calculated for each trapping site the average rainfall over 20 years (1993-2013) and the rainfall of the month of capture. In order to assess the impact of cumulative rainfall on leptospirosis, we also calculated the rainfall for the month preceding the capture, as well as the cumulative rainfall for the two and three previous months.

\subsection{Cartography}

We used QGIS software for mapping the results. The Infectious Disease Surveillance Unit of the Ministry of Health provided human leptospirosis data for the 22 districts of Mahé for the year 2015 only. These data do not allow a study of human epidemiology and this was not the purpose of this study, but we used them to contextualize rodent data on a map. We obtained publicly available district population data from the National Bureau of Statistics of Seychelles that were used to calculate and map the incidence of leptospirosis by district. We used a district contour map provided by the Ministry of Habitat, Infrastructure and Land Transport of the Republic of Seychelles.

\subsection{Statistical Analyses}

We performed all statistical analyses using the R 3.4.3 language and environment for statistical computing [39]. Statistical significance was set at $p<0.05$. We conducted descriptive analyses at the scale of the trapping sites and more precisely at the scale of the individuals located by the GPS of the trapping site. We verified if the number of samples trapped at each site was sufficient to detect statistically significant positivity by using a Poisson distribution, based on the average prevalence of the species. To test the variables that discriminate between groups of positive/negative rats, we performed an exact Fisher's test on qualitative/categorical variables, and a Student's test on continuous/numerical variables. We represented the most discriminating variables to be included in the final model using a principal component analysis (PCA). For the multivariate analysis, we decomposed the dataset into two subdatasets: learning/training data and test data. We used the caret package to perform a logistic regression with k-fold repeated cross-validation ( $k=5$, repeated 5 times) on the learning set by testing the discrimination of positive/negative rats according to all environmental variables kept for the analysis. 
The stepwise method, based on the AIC criterion, allowed us to define the optimal model. Finally, we assessed the accuracy of the model from the receiver operating characteristic (ROC) curve or the precision-recall (PR) curve when the dataset is imbalanced, by using the PRROC package [40].

\section{Results}

\subsection{Trapping Success}

A total of 735 murine rodents were captured during the 1856 trap-nights of the study and included in this analysis (Table 1, see also Biscornet et al. 2017 [14] for a comprehensive description of the sample). They belong to two species: 685 Rattus rattus (RR) and 50 Rattus norvegicus (RN). No Mus musculus were captured, probably because of the large size of the cage traps used.

Table 1. Rodents trapping results and Leptospira infection prevalence by sample site. The type of environment is provided for each site: urban $(\mathrm{U})$, peri-urban $(\mathrm{P})$, rural $(\mathrm{R})$ and natural $(\mathrm{N})$.

\begin{tabular}{|c|c|c|c|c|c|c|c|}
\hline \multirow[t]{2}{*}{ Site } & \multirow[t]{2}{*}{ Trap-Nights } & \multirow[t]{2}{*}{ Environment } & \multicolumn{3}{|c|}{ Trapping Success } & \multicolumn{2}{|c|}{$\begin{array}{c}\text { Leptospira Detection (RT-qPCR) } \\
\text { Positive/Total Sampled } \\
\text { (\% of Positive) }\end{array}$} \\
\hline & & & Rattus rattus & $\begin{array}{c}\text { Rattus } \\
\text { norvegicus }\end{array}$ & Rattus rattus & $\begin{array}{c}\text { Rattus } \\
\text { norvegicus }\end{array}$ & All \\
\hline Casse Dent & 149 & $\mathrm{~N}$ & 46.9 & 0.0 & $2 / 65(3.1)$ & $0 / 2(0.0)$ & $2 / 67(3.0)$ \\
\hline Chemin Dame le Roi & 179 & $\mathrm{R}$ & 47.9 & 0.0 & $2 / 75(2.7)$ & & $2 / 75(2.7)$ \\
\hline Fairview La Misère & 250 & $\mathrm{P}$ & 31.2 & 10.3 & $8 / 69$ (11.6) & $8 / 15(53.3)$ & $16 / 84(19.0)$ \\
\hline $\begin{array}{l}\text { Grand Bois Mont } \\
\text { Cephale }\end{array}$ & 140 & $\mathrm{~N}$ & 47.2 & 0.0 & $3 / 58(5.2)$ & - & $3 / 58(5.2)$ \\
\hline La Gogue & 133 & $\mathrm{R}$ & 54.0 & 1.7 & $1 / 66(1.5)$ & $0 / 1(0.0)$ & $1 / 67(1.5)$ \\
\hline La Reserve & 172 & $\mathrm{~N}$ & 36.6 & 0.0 & $1 / 60(1.7)$ & - & $1 / 60(1.7)$ \\
\hline Police Bay & 168 & $\mathrm{~N}$ & 60.0 & 0.0 & $0 / 98(0.0)$ & - & $0 / 98(0.0)$ \\
\hline Port Launay & 148 & $\mathrm{R}$ & 57.9 & 6.3 & $2 / 78(2.6)$ & $3 / 5(60.0)$ & $5 / 83(6.0)$ \\
\hline $\begin{array}{c}\text { Providence Industrial } \\
\text { Estate }\end{array}$ & 33 & $\mathrm{U}$ & 39.3 & 10.5 & $0 / 6(0.0)$ & $2 / 2100.0$ & $2 / 8(25.0)$ \\
\hline $\begin{array}{c}\text { Reclaimed Land } \\
\text { (Zone 21) }\end{array}$ & 142 & $\mathrm{P}$ & 37.3 & 5.6 & $7 / 50(14.0)$ & $5 / 5(100.0)$ & $12 / 55(21.8)$ \\
\hline Victoria & 342 & $\mathrm{U}$ & 18.4 & 7.4 & $4 / 60(6.7)$ & $9 / 20(45.0)$ & $13 / 80(16.3)$ \\
\hline Total & 1859 & & 43.3 & 3.8 & $30 / 685$ (4.4) & $27 / 50(54.0)$ & $57 / 735(7.8)$ \\
\hline
\end{tabular}

There was an average 158 trap-nights per site. The trapping effort was lower at Providence Industrial Estate with only 32 trap-nights for logistic reasons, whereas the other 10 sites had at least 128 trap-nights. RR were trapped at all sites and averaged $43.3 \%$ with a maximum of $60.0 \%$ trapping rate at Police Bay. RN trapping was less successful (at 6 sites). The average trapping rate for $\mathrm{RN}$ was $3.8 \%$ and reached a maximum of $10.5 \%$ at Providence Industrial Estate and 10.3\% at Fairview La Misère. There was no correlation between the percentages of trapping success of the two species per site. In the sampling sites where RN were caught, the trapping rates of RR were among the lowest. When calculating the global trapping rates (both species indifferently), the standard deviation decreases to $10.8 \%$ with an average of $44.9 \%$ (Figure 1 ). 


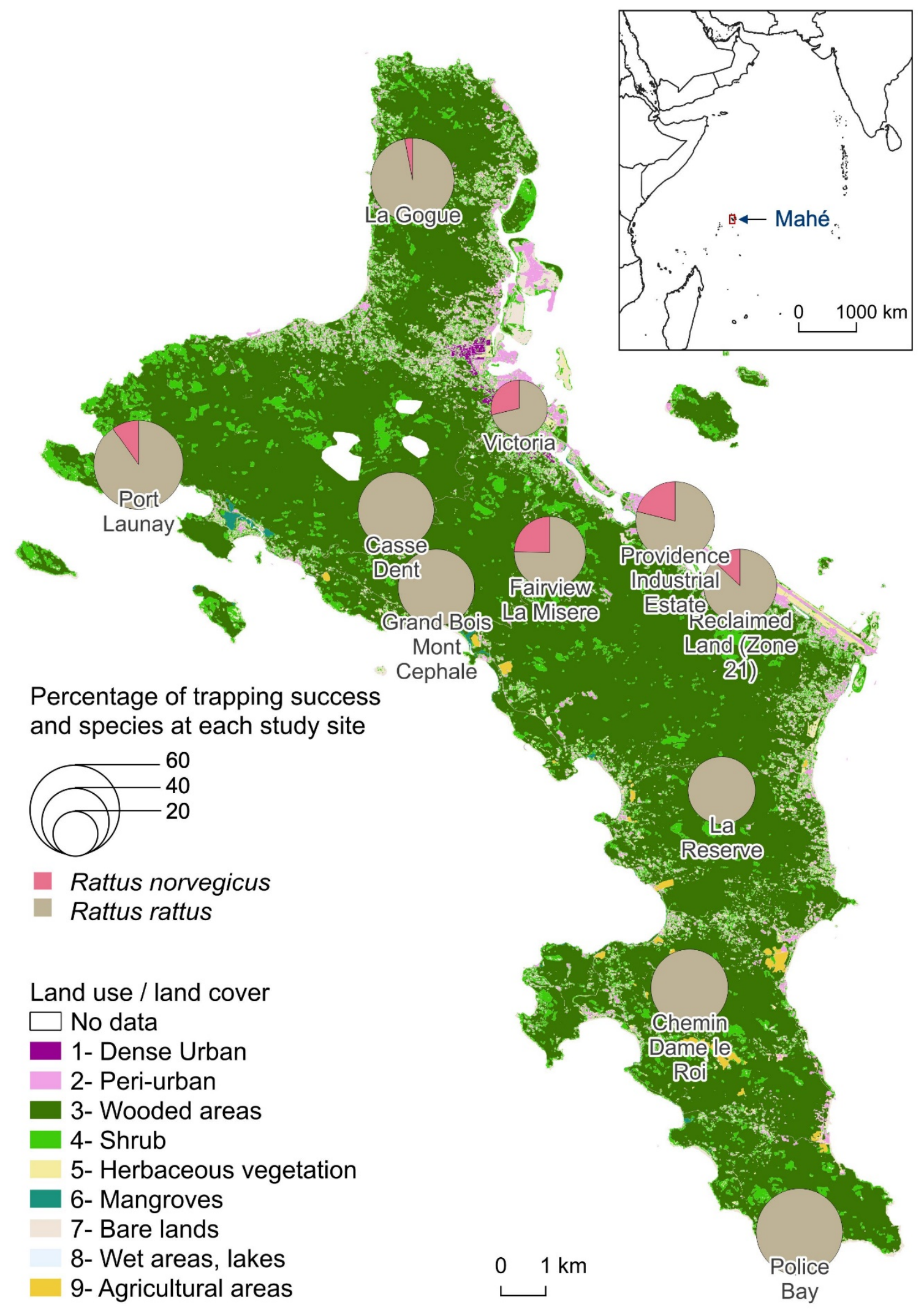

Figure 1. Percentage of trapping success of Rattus norvegicus and Rattus rattus at each study site. 


\subsection{Rat Characteristics}

The sex ratio of males to females differed according to species although not significantly: 1.5 for RN (30/20) and 1.1 for RR (351/322) while 12 animals could not be defined as male or female. The adult to juvenile ratio was also higher for RN (15.7, i.e., 47 adults for 3 juveniles) than for RR (5.4, i.e., 578 adults for 107 juveniles), because very few RN juveniles were captured during sampling. For each species, adult males were larger in size and mass than adult females, not significantly (Student test $p=0.07$ ) for RN (average head and body length for $\mathrm{RN}$ males $=229.6 \mathrm{~mm}$, RN females $=216.7$ ) and significantly $(p<<0.001)$ for RR (RR males $=182.8$, RR females $=172.7)$. We also observed that the adult RN caught during the dry season were significantly heavier on average $(278.4 \mathrm{~g})$ than those caught during the wet season $(218.2 \mathrm{~g})$. Adult RR had similar weight in both seasons (119.9 $\mathrm{g}$ during the dry season and $122.5 \mathrm{~g}$ during the wet season).

\subsection{Renal Carriage of Leptospira spp.}

The overall prevalence of Leptospira infection was $7.8 \%(57 / 735)$ with a prevalence in RN (54.0\%) significantly higher than in RR (4.4\%) (Table 1). Maturity had no effect on infection in RR, positivity rate being similar in juveniles ( $4.7 \%, 5$ positive for 107 juveniles) and in adults (4.3\%, 25 positive for 578 adults). None of the three juvenile RN tested positive for leptospirosis, but their number is too small to test whether it is significant or not. In addition, there were no significant differences by gender for all animals tested and for both species. Positive adult RN were significantly larger in size $(231.4 \mathrm{~mm})$ than negative adult RN $(214.1 \mathrm{~mm})$ (Student test $p<0.05)$ unlike for adult RR $(176.2 \mathrm{~mm}$ for positive adult RR and 177.4 for negative) (Figure 2).

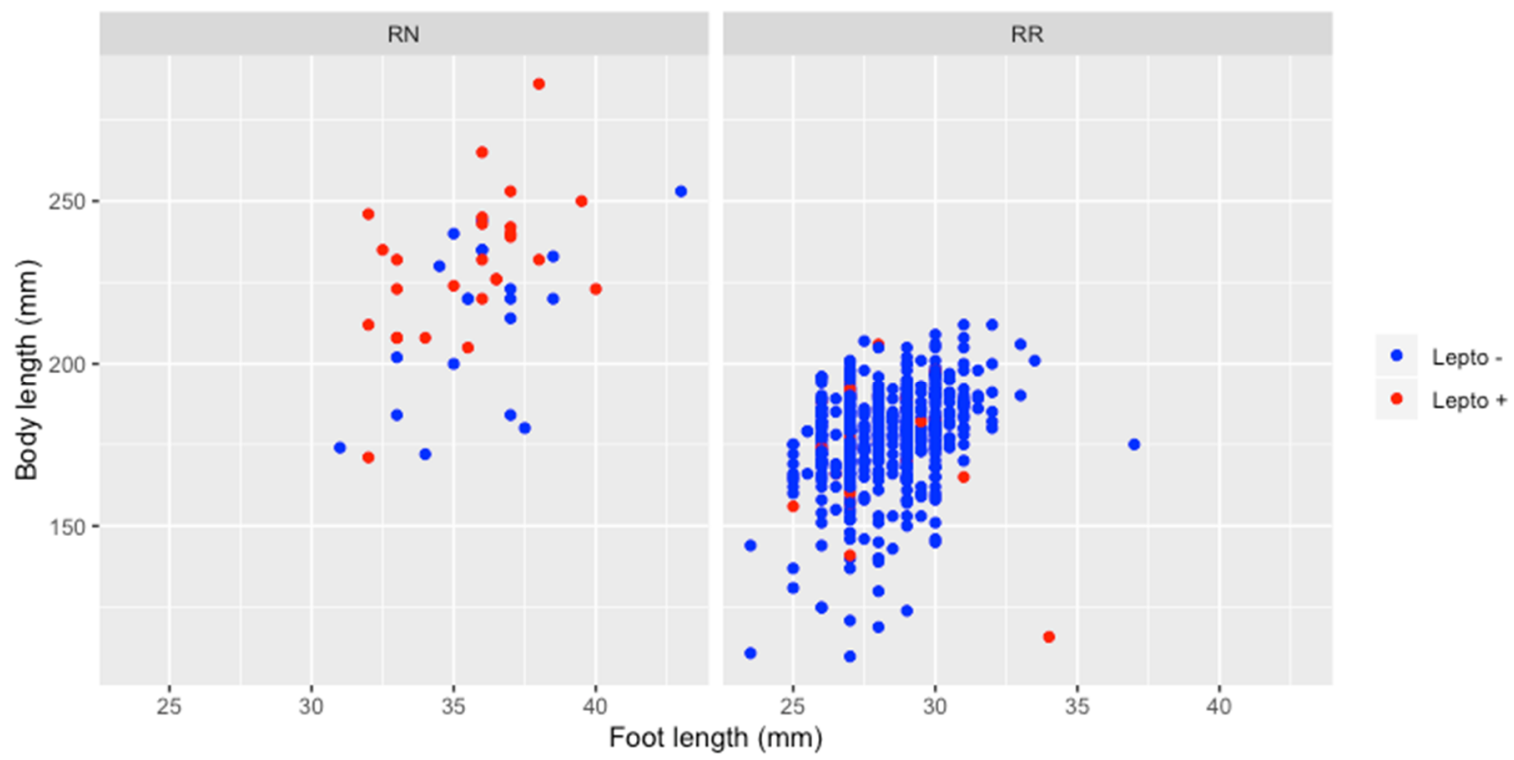

Figure 2. Relation between animal size (regarding body and foot length) and Leptospira infection, for Rattus norvegicus and Rattus rattus.

Leptospira-infected animals were found in 10 of the 11 sampled sites but with clearly distinct species distribution and infection prevalence (Table 1, Figure 3). At Police Bay, none of the 98 trapped rats $(100 \% \mathrm{RR})$ were found positive for leptospire. RN were found highly prevalent only at two sites, with similar infection prevalence: $45.0 \%(9 / 20)$ at Victoria and $53.3 \%(8 / 15)$ at Fairview La Misère (central Mahé, about $500 \mathrm{~m}$ high and 4-5 km south of the city of Victoria). RR were rarely captured on one site (Providence Industrial Estate) and were all noninfected. For the other 10 sites, a minimum of $50 \mathrm{RR}$ was caught per site with an average prevalence of $4.4 \%(30 / 679)$ and a standard deviation of $4.6 \%$. The highest 
RR prevalence was reported from Reclaimed Land (Zone 21) $(14 \%, 7 / 50)$ and Fairview La Misère $(11.6 \%, 8 / 69)$.

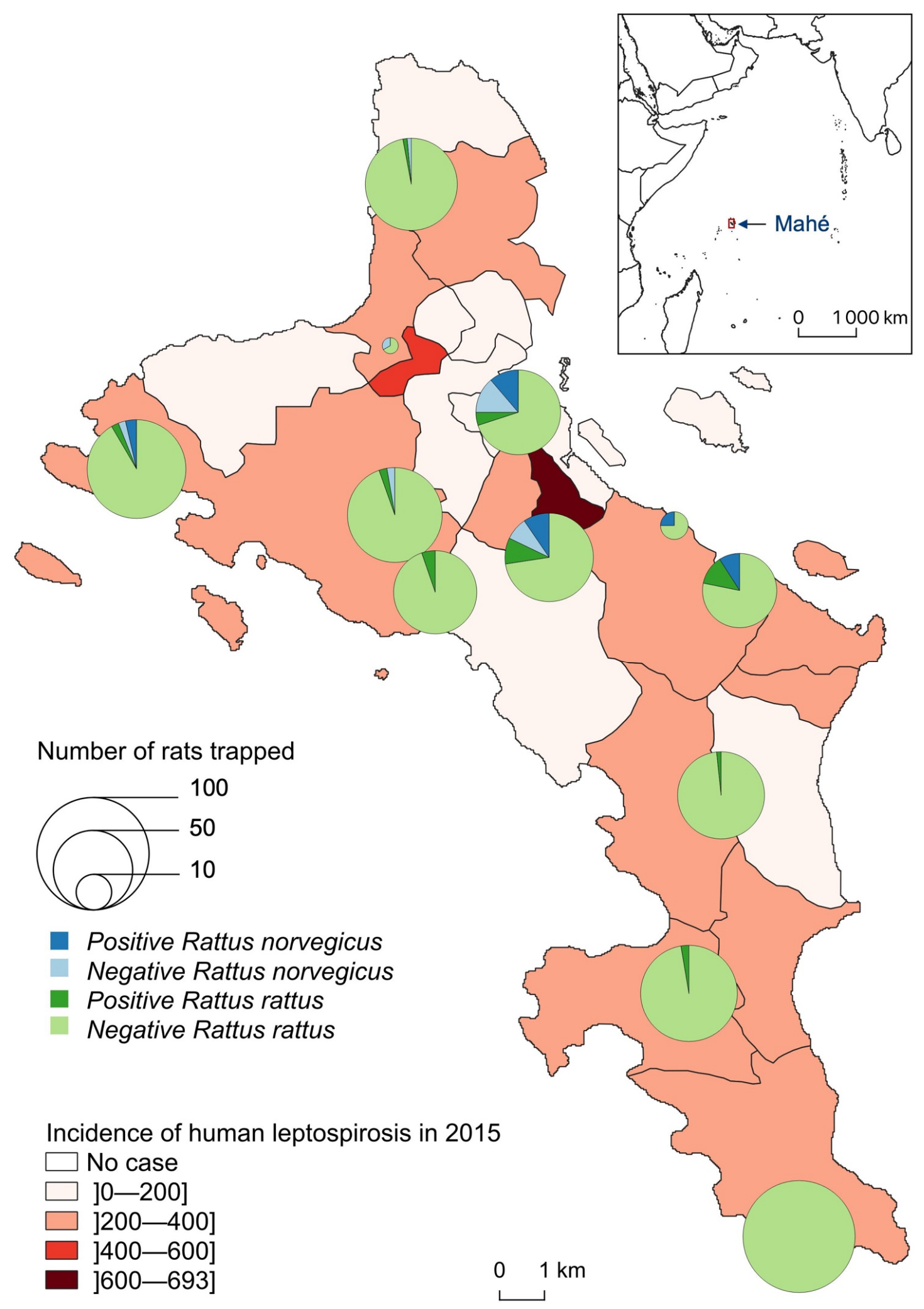

Figure 3. Number of Leptospira-infected (positive) and noninfected (negative) Rattus trapped, by species and site, compared to the incidence of human leptospirosis by district in 2015 (for 100,000 inhabitants). 


\subsection{Ecological Pattern of Rat Distribution}

The final land use/land cover map includes nine classes (1-Dense Urban, 2-Periurban, 3-Wooded areas, 4-Shrub, 5-Herbaceous vegetation, 6-Mangroves, 7-Bare lands, 8-Wet areas, lakes, 9-Agricultural areas). We recorded 390 observations in the field to validate the classification (Table 2). The confusion matrix allowed us to calculate a Kappa index of 0.88 , which is very satisfactory for future uses of this classification. The least accurate class was bare soils due to confusion with the two urban classes that have similar spectral signatures. From this classification, we calculated 43 landscape indices to be used for statistical analyses. We also calculated five meteorological variables to complete the dataset.

Table 2. Confusion matrix of the land use/land cover classification.

\begin{tabular}{|c|c|c|c|c|c|c|c|c|c|c|c|}
\hline Land Use/Land Cover Classes & 1 & 2 & 3 & 4 & 5 & 6 & 7 & 8 & 9 & Total & Producer Accuracy \\
\hline 1-Dense Urban & 39 & & & & 2 & & 3 & & & 44 & 0.89 \\
\hline 2-Peri-urban & & 56 & 3 & 2 & 1 & & 4 & & & 66 & 0.85 \\
\hline 3-Wooded areas & & & 79 & & & 2 & & & & 81 & 0.98 \\
\hline 4-Shrub & & & 4 & 28 & & & & 1 & & 33 & 0.85 \\
\hline 5-Herbaceous vegetation & & 1 & 2 & 1 & 25 & & 5 & & & 34 & 0.74 \\
\hline 6-Mangroves & & & 2 & 2 & & 26 & & & & 32 & 0.81 \\
\hline 7-Bare lands & & & & 2 & & 1 & 33 & 3 & & 39 & 0.85 \\
\hline 8-Wet areas, lakes & & & & & & 1 & & 29 & & 30 & 0.97 \\
\hline 9-Agricultural areas & & 1 & & & 1 & & & & 31 & 33 & 0.94 \\
\hline Total & 39 & 58 & 90 & 35 & 29 & 30 & 45 & 33 & 31 & 390 & \\
\hline User accuracy & 1 & 0.97 & 0.88 & 0.80 & 0.86 & 0.87 & 0.73 & 0.88 & 1 & & \\
\hline
\end{tabular}

Both rat species could be trapped over the entire range of altitudes with close averages (149.6 $\mathrm{m}$ for RN and $154.6 \mathrm{~m}$ for RR) (Figure 4A). Nevertheless, the majority of RN was caught at lower altitudes (with a median of $9 \mathrm{~m}$ for RN and $123 \mathrm{~m}$ for RR). In addition, for both species, Leptospira-infected rats were found at a lower median elevation than noninfected ones, but the effect of altitude is not significant on positivity. Of note, in Mahé Island, altitude is correlated with land use and proximity to urban areas, which are mostly located in coastal areas (i.e., low altitude). Of the nine land use/land cover classes, four of them show a significantly different distance between the two groups of infected/noninfected rats. Infected rats of both species were observed at similar distances from dense urban areas (with a median of $2513 \mathrm{~m}$ for RN and $3548 \mathrm{~m}$ for RR) while uninfected $\mathrm{RN}$ were observed at shorter distances $(1629 \mathrm{~m})$ and noninfected $\mathrm{RR}$ at greater distances $(4985 \mathrm{~m})$ with significant differences $(p<0.001)$ (Figure $4 \mathrm{~B})$. Noninfected rats were also significantly observed at greater distances from peri-urban areas (with a median of $71 \mathrm{~m}$ for RR and $16 \mathrm{~m}$ for RN) than infected rats for both species (with a median of $16 \mathrm{~m}$ for $\mathrm{RR}$ and $13 \mathrm{~m}$ for $\mathrm{RN})(p<0.001)$. These results are the same from shrub areas $(p<0.001)$ and bare lands $(p<0.001)$. Finally, the fragmentation index (edge density) also differentiated between infected and noninfected rats for both species. Amongst the three buffer sizes, the index calculated within a radius of $100 \mathrm{~m}$ appeared as the most discriminating (Figure 4C). The median of the edge density $(100 \mathrm{~m})$ of infected RR was almost twice $(0.44)$ that of noninfected RR (0.22) and 1.1 times higher for infected $\mathrm{RN}(0.63)$ compared to noninfected RN (0.56). 

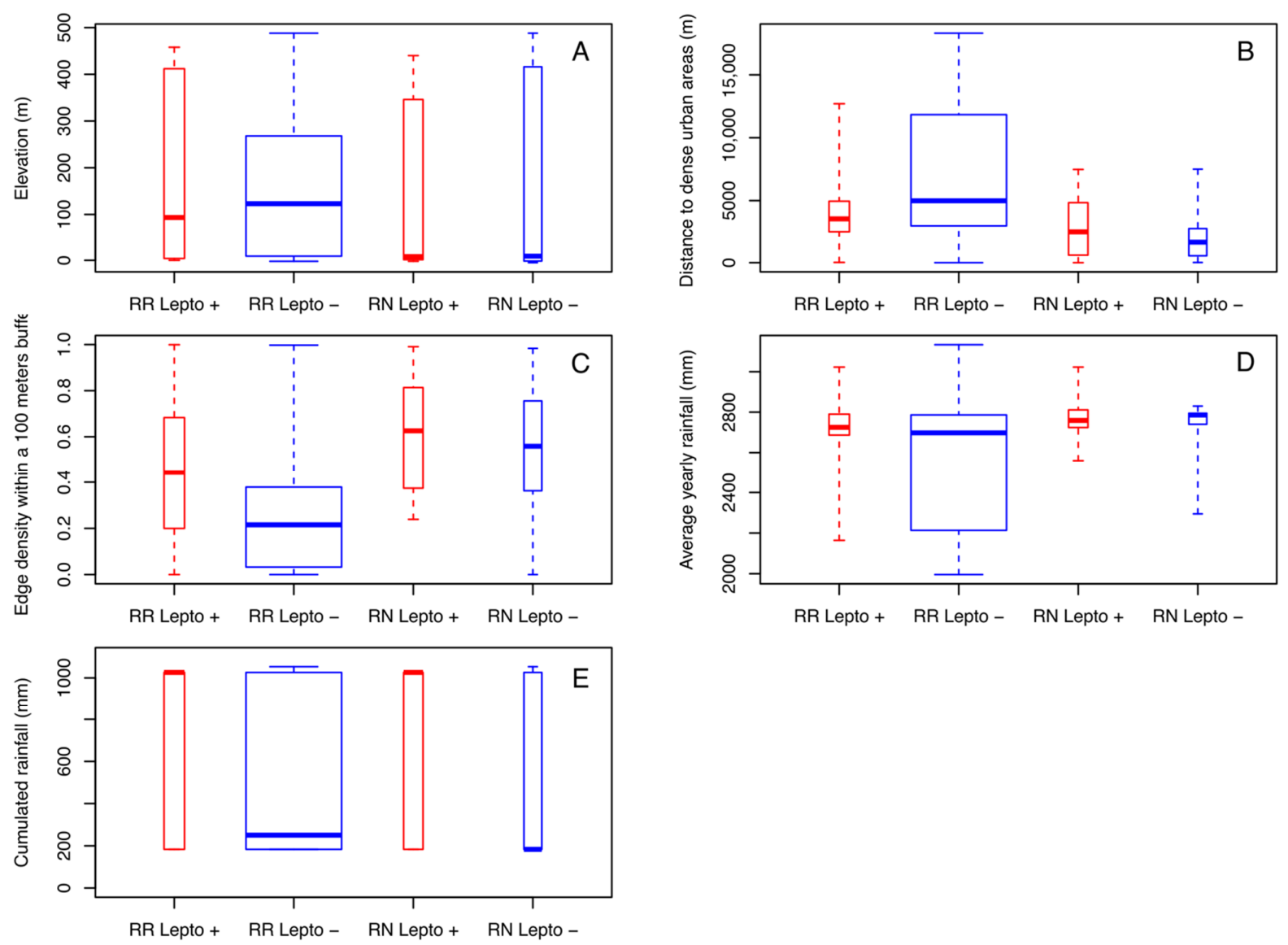

Figure 4. Boxplots of the most discriminant environmental variables, by species and Leptospira infection, measured from each sampling site: (A) elevation, (B) distances to dense urban areas, (C) edge density within a $100 \mathrm{~m}$ buffer, (D) average yearly rainfall, (E) cumulated rainfall during three months before capture.

Rain appeared as a factor influencing the distribution and infection rates of rats. First of all, rats sampled in the drier locations (according to the 20-year average yearly rainfall) were mostly noninfected RR $(p<0.001)$ (Figure $4 \mathrm{D})$. The cumulated rainfall during the three months preceding the capture was also a discriminating variable $(p=0.01833)$ (Figure $4 \mathrm{E}$ ). Infected rats were sampled in places or during periods with more rainfall. Median values for infected rats were four (for RR) to over six times (for RN) higher than those of noninfected rats (1026 mm for positive RR and RN, $250 \mathrm{~mm}$ for negative RR and 183 for negative $\mathrm{RN}$ ).

By projecting the variables on the first two axes (which account for $83.6 \%$ of the total inertia), PCA showed that the distance to urban areas distinguishes noninfected RR from other rats. By contrast, the occurrence of infected RR and all RN (regardless of their infection status) was associated with higher rainfall and habitat fragmentation (Figure 5).

\subsection{Environmental Prediction of Leptospires Carriage}

First, we kept for the multivariate modeling the eight variables previously identified as relevant: edge density within a $100 \mathrm{~m}$ buffer, distances to dense urban areas, distances to peri-urban areas, distances to shrubs, distances to bare lands, average rainfall over the last 20 years, cumulated rainfall during three months before capture and elevation. We applied a logistic regression with stepwise function on the learning dataset (Table 3). The edge density and average rainfall variables are the only ones that discriminate leptospirosiscarrying rats from healthy rats ( $p<0.001$ and $p=0.023$, respectively). Areas with high edge density and high average rainfall will have more carrier rats. However, the area under the curve (AUC) from PR (since the carrier/healthy and observed/predicted groups are 
imbalanced) is very low (16.08\%) (Figure 6). Then this first model could not predict the carriage of leptospires, neither in the test nor in the learning dataset.
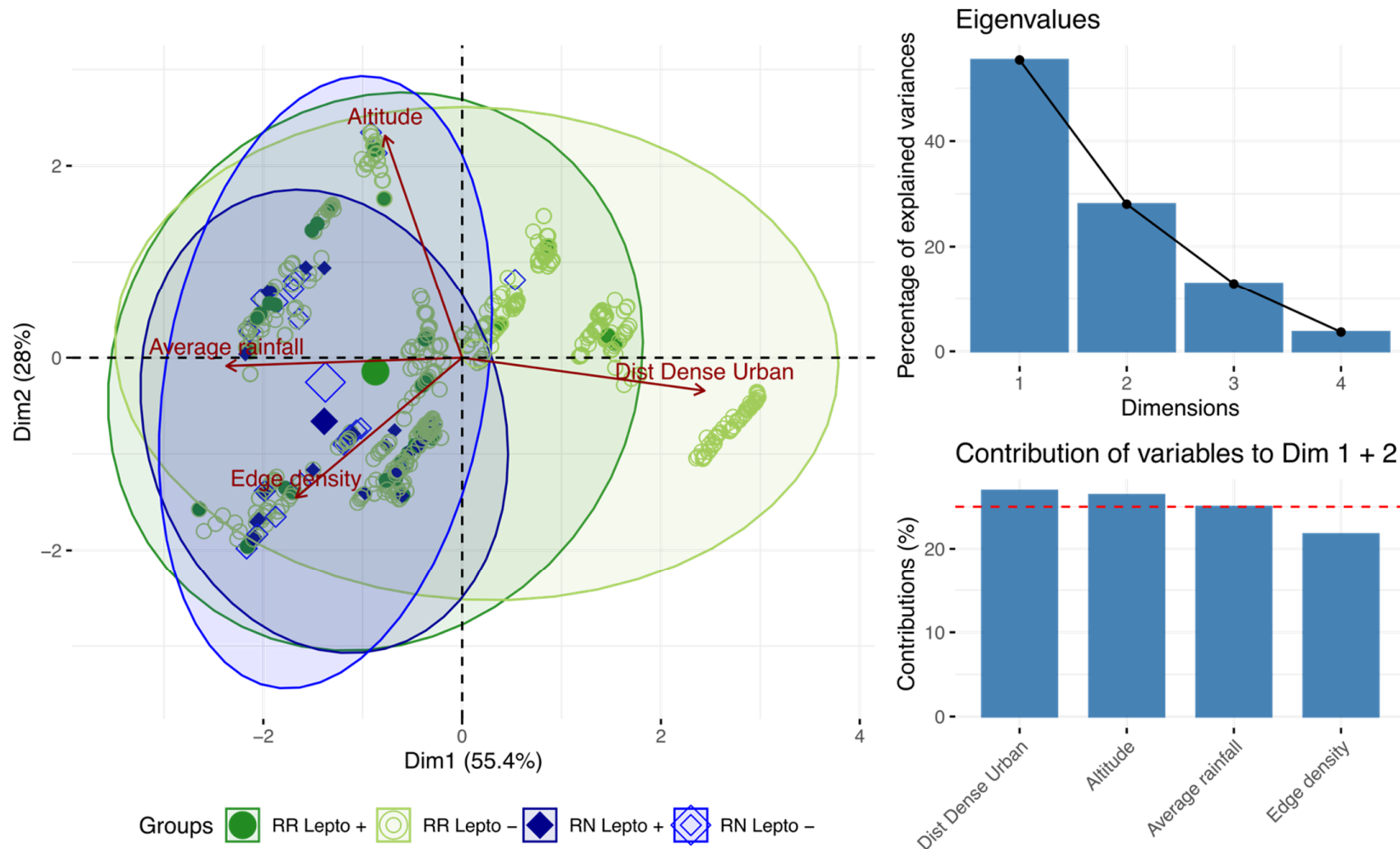

Contribution of variables to $\operatorname{Dim} 1+2$

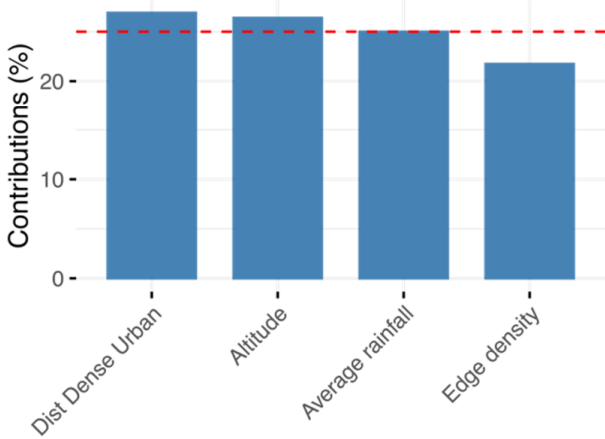

Figure 5. Principal component analysis showing the most discriminating variables.

Table 3. Models obtained with logistic regressions to explain the carriage of leptospires (infected vs. noninfected).

\begin{tabular}{|c|c|c|c|c|c|}
\hline Model & Variables & Estimate & Std. Error & $z$ Value & $p$-Value \\
\hline Model 1 (Excluding variable Species) & (Intercept) & -2.943 & 0.238 & -12.382 & $<2 \times 10^{-16}$ \\
\hline $\mathrm{AIC}=272.74$ & Edge density 100 & 0.591 & 0.160 & 3.683 & $<3 \times 10^{-4}$ \\
\hline \multirow{3}{*}{$\begin{array}{c}\text { AUC }_{\mathrm{ROC}}=77.68 \% \\
\text { AUC }_{\mathrm{PR}}=16.08 \% \\
\text { Accuracy }=92.35 \% \\
\text { F1 = NA }\end{array}$} & 20 -year average rainfall & 0.643 & 0.283 & 2.272 & 0.023 \\
\hline & 3-month cumulated rainfall & 30.260 & 0.159 & 1.629 & 0.103 \\
\hline & Elevation & 0.219 & 0.144 & 1.526 & 0.127 \\
\hline \multirow{5}{*}{$\begin{array}{c}\text { Model } 2 \text { (Excluding variable Species) } \\
\text { AIC }=272.14 \\
\mathrm{AUC}_{\mathrm{ROC}}=79.42 \% \\
\mathrm{AUC}_{\mathrm{PR}}=15.55 \% \\
\text { Accuracy }=92.35 \% \\
\mathrm{~F} 1=\mathrm{NA}\end{array}$} & (Intercept) & -2.925 & 0.233 & -12.548 & $<2 \times 10^{-16}$ \\
\hline & Edge density 100 & 0.499 & 0.177 & 2.81 & 0.005 \\
\hline & Distances to dense urban areas & -0.738 & 0.317 & -2.332 & 0.020 \\
\hline & 3-month cumulated rainfall & 0.247 & 0.159 & 1.555 & 0.120 \\
\hline & & & & & \\
\hline \multirow{5}{*}{$\begin{array}{c}\text { Model } 3 \text { (Including variable Species) } \\
\text { AIC }=237.9 \\
\mathrm{AUC}_{\mathrm{ROC}}=88.12 \% \\
\mathrm{AUC}_{\mathrm{PR}}=47.21 \% \\
\mathrm{Accuracy}=93.99 \% \\
\mathrm{~F} 1=42.11 \%\end{array}$} & (Intercept) & -3.034 & 0.235 & -12.907 & $<2 \times 10^{-16}$ \\
\hline & Species RR & -0.648 & 0.107 & -6.044 & $1.5 \times 10^{-9}$ \\
\hline & Edge density 100 & 0.380 & 0.195 & 1.947 & 0.052 \\
\hline & Distances to dense urban areas & -0.395 & 0.305 & -1.294 & 0.195 \\
\hline & 3-month cumulated rainfall & 0.21 & 0.17 & 1.251 & 0.211 \\
\hline \multirow{6}{*}{$\begin{array}{c}\text { Model } 4 \text { (Including variable Species) } \\
\text { AIC }=236.65 \\
\mathrm{AUC}_{\mathrm{ROC}}=84.87 \% \\
\mathrm{AUC}_{\mathrm{PR}}=43.07 \% \\
\text { Accuracy }=92.35 \% \\
\mathrm{~F} 1=30 \%\end{array}$} & (Intercept) & -3.1093 & 0.254 & -12.246 & $<2 \times 10^{-16}$ \\
\hline & Species RR & -0.657 & 0.105 & -6.242 & $4.3 \times 10^{-10}$ \\
\hline & Edge density 100 & 0.3835 & 0.180 & 2.132 & 0.033 \\
\hline & 20 -year average rainfall & 0.5217 & 0.304 & 1.718 & 0.086 \\
\hline & 3-month cumulated rainfall & 0.2302 & 0.176 & 1.309 & 0.190 \\
\hline & Elevation & 0.2125 & 0.158 & 1.348 & 0.178 \\
\hline
\end{tabular}



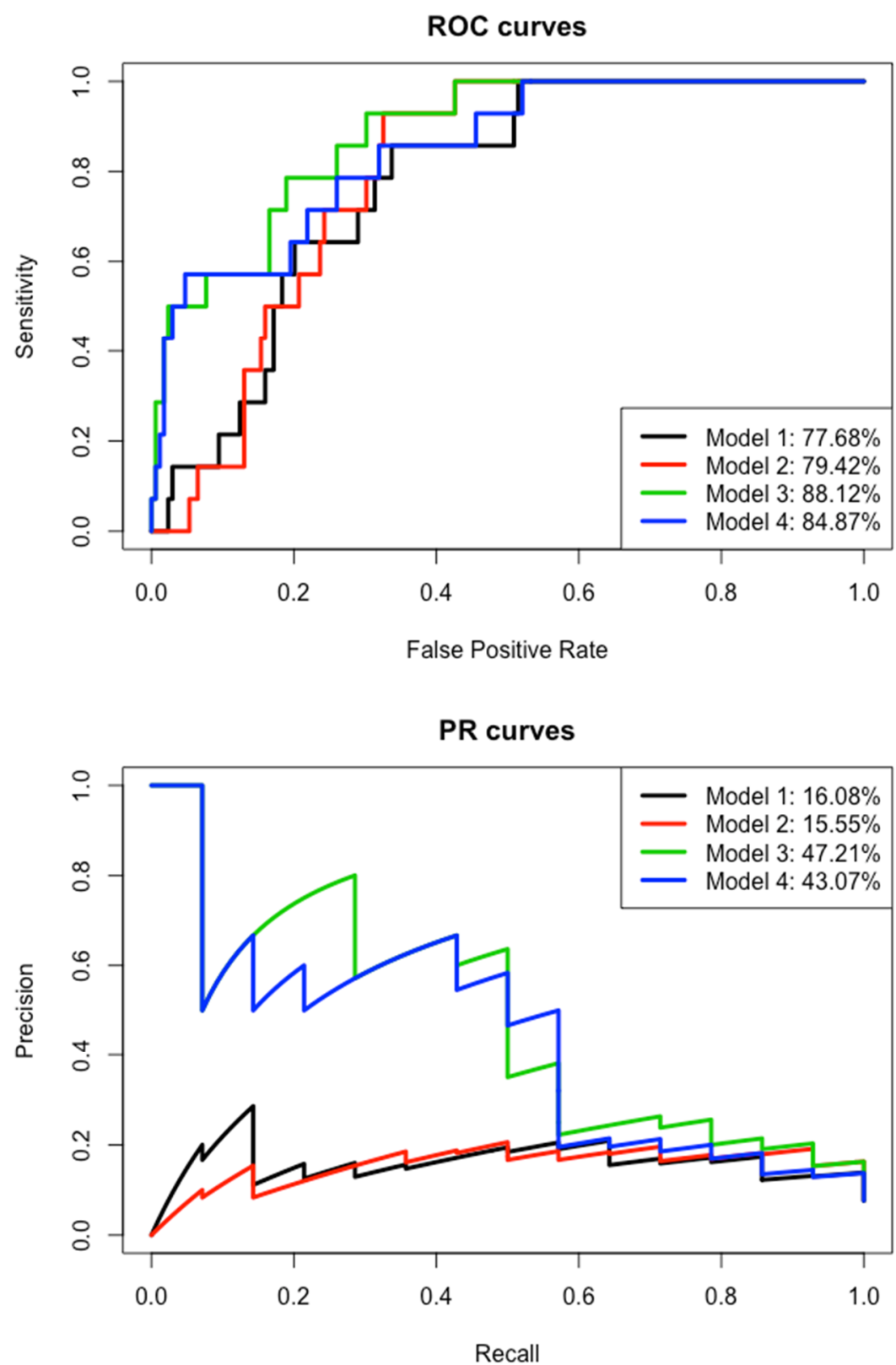

Figure 6. Receiver operating characteristic (ROC) curves and precision-recall (PR) curves of the four models.

After removing the average rainfall variable, the cumulated rainfall and edge density remain included in the second model with little change in their estimate (Table 3). The variable "distances to dense urban areas" is strongly significant in this second model, whereas it was removed in the first one, contrary to the altitude. The AIC is similar between the two models and the areas under the curve are also comparable for ROC and PR (Figure 6). We can assume that average rainfall can be replaced by the distances to dense urban areas. Furthermore, this second model is unable to predict leptospires carriage.

By keeping the remaining variables in the second model and adding the "species" variable, the third model is more accurate with a smaller AIC and much greater AUCs, especially for PR AUC ( $47.21 \%$ versus $15.55 \%$ in the second model) (Table 3 and Figure 6$)$. The "species" variable is highly significant $(p<0.001)$ and its inclusion has an impact on the "edge density" variable, which falls just above the significant threshold and "distances to dense urban areas" variable that is no longer significant. Then, the significant effect of these two variables in the second model is mainly explained by the species effect. Indeed, the vast 
majority of healthy rats are RRs that were captured in less fragmented areas and at a greater distance from urban areas. Meanwhile, the inclusion of the "species" variable had very few effects on the cumulated rainfall (similar estimates in models 2 and 3). This third model allows the prediction of leptospirosis carriage, with a sensitivity of $28.57 \%$ for a specificity of $99.41 \%$ on the test dataset (or precision $=50 \%$ and recall $=28.57 \%$ for $\mathrm{F} 1=42.11 \%$, harmonic/weighted average of precision and recall, in the case of imbalanced data).

By keeping the remaining variables in the first model and adding the "species" variable, the fourth model is also more accurate with a smaller AIC and much greater AUCs, especially the PR AUC (43.07\% compared to $16.08 \%$ in the first model) (Table 3 and Figure 6). The "species" variable is highly significant $(p<0.001)$ and the "edge density" remains significant, but less than for the first model $(p=0.033$ versus $p<0.001)$. As for the third model, this fourth one allows the prediction of leptospirosis carriage, even if it remains very low: sensitivity of $21.43 \%$ for a specificity of $98.23 \%$ on the test dataset (or precision $=50 \%$ and recall $=21.43 \%$ for $\mathrm{F} 1=30 \%$ ).

\section{Discussion}

\subsection{Rattus Diversity and Abundance}

Rodent trapping confirms the widespread presence on Mahé Island of the two most common invasive commensal rodents ( $R R$ and $R N$ ). The high trapping rate of RR (average at $43.3 \%$ and highest at $60 \%$ ) reflects its relative higher abundance compared to $\mathrm{RN}$, which was trapped less frequently (average of $3.8 \%$ and highest of $10.5 \%$ ) and mostly in or close to urban areas. In addition, the coexistence of both rat species tends to modify the frequency of the two species due to competition, the presence of RN being correlated with less RR on a site. This phenomenon has been demonstrated in studies on various animals, including Rattus spp. [41,42].

Studies have shown that rodent trapping rate varies greatly over time. Sampling twice does not allow us to understand the dynamics of rodent populations and studies have shown that it is necessary to increase the number of trapping sessions over time, in particular to better assess peaks in abundance [43]. However, our study focuses here on capturing relative abundances and leptospires carriage. Spatially, trapping rates can be very different from one country to another and from one setting to another. Recently in Salvador, Brazil, a study reported $13.1 \%$ of RN trapping rate [44], to be compared to $1.5 \%$ in Buenos Aires, Argentina [45]. The rat density seen on Mahé Island, Seychelles, could not be estimated as this study was not designed to answer that question; however, high trapping rates ( $47.1 \%$ for both Rattus spp.) suggest a high abundance. This is generally expected on oceanic tropical islands due to the paucity of competitors and predators together with an abundance of suitable habitats and food sources for rats during much of the year [46]. Of note, a survey carried out on La Réunion Island by the same trapping team led to a trapping rate of $17.0 \%$ (808 RR and RN caught with 4762 trap-nights), hence suggesting that rat abundance is particularly high in Seychelles, as previously reported by conservationoriented research programs on various Seychelles islands, such as the Aldabra Atoll, Mahé, Frégate and other granitic islands [46-48].

\subsection{Leptospira-Laden Rattus spp.}

A higher Leptospira carriage in RN, compared to RR, is consistent with observations reported in many other countries. In Thailand, a meta-analysis of several surveys on murine rodents showed a prevalence of $20.8 \%(179 / 860)$ for RN compared to $5.8 \%(107 / 1858)$ for Rattus tanezumi, a Rattus rattus lineage [49]. In addition, a meta-analysis of worldwide surveys on Leptospira carriage in RN reported an average prevalence of $20-25 \%$ with possible higher prevalence in specific countries [50], such as in a suburban area in Copenhagen, Denmark, where $53 \%$ of RN were found infected with Leptospira spp. [51] and in slums in Salvador, Brazil, where $88 \%$ of RN were infected [52]. Rarely, reverse trends have been shown; in the Los Rios region of Chile, Leptospira infection was $20.7 \%(51 / 246)$ in RR compared to $10.3 \%$ in $\mathrm{RN}$, but the study was based on a small sample size $(\mathrm{N}=29)$ [53]. 


\subsection{Rattus Characteristics in Relation to Infection Rates}

Rats generally reach a larger size on tropical islands in view of the known island rule ecological hypothesis, which negatively correlates body size to co-occurring mammalian species; for instance, Pacific islands have recorded gigantism in the invasive rodent Rattus exulans [54]. Although not significantly different, size differences between males and females were observed and may be related to the natural attribute of sexual dimorphism [44].

Captured RR were homogeneous with a sex ratio close to one, a relatively large number of juveniles and a homogeneous weight according to the seasons. In contrast, for captured RN, males were caught in greater numbers than females, and very few young were caught. This reflects the differences in behavior between the two species, with RN females probably less mobile than RR females and a more conservative behavior for $\mathrm{RN}$ to protect their progeny. Indeed, $\mathrm{RN}$ are social animals that live in groups in their burrows [55]. They groom each other and females help each other to raise the juveniles [32].

Rural rats generally grow at a lower rate compared to urban rats. This has been postulated to be due to the relative abundance of nutritional sources compounded with less competition for it, in urban areas compared to rural areas, as well as the abundance of possible shelters afforded by urban landscapes [45,56,57]. This rapid reproductive capacity allows RNs to quickly colonize spaces. Knowing that they have high Leptospira prevalence, their population dynamics can create potential conditions for outbreaks or latency of leptospirosis.

\subsection{Environmental Factors in Relation to Rat Distribution and Infection Rates}

Mahé is a hilly island, with protected natural parks on its heights and the most populated areas on the coast. Trapping has revealed that rats are present on all sites, distributed throughout the island. However, spatial distribution differs between the two species. RR is the less selective species and is found at all altitudes and in all environments, which corresponds to the known ecology of this commensal species [58]. Most RN were trapped at lower altitudes in urban settings. It should be noted that these urban areas include natural soil (an overlap also noted in the classification, "bare soils"), which is therefore the ideal environment for $\mathrm{RN}$, as it tends to create its own shelter by digging burrows [59]. Rat movement has been shown to be restricted by food and shelter availability as well as physical features such as roads and waterways [60]. Associated with the fact that $\mathrm{RN}$ was relatively newly introduced [61], this may additionally explain the foci of $\mathrm{RN}$ in these urban landscapes.

The ecology of the two investigated Rattus species may at least in part drive the contrasting prevalence of infection observed, as RR is arboreal while RN nests in burrows, hence probably more exposed to environmental Leptospira. The different distributions of the two Rattus species, combined with a very high leptospires carrying rate in RN (12 times higher than RR), make the distribution of leptospires in rats logically similar to the heterogeneous distribution of RN. However, a few infected RR have been identified in the southern part of the island, at the heights of La Reserve (1.7\% infected) and Chemin Dame le Roi (2.7\% infected). No infected rats, however, were found in the extreme southern part of the island, at Police Bay (where no RN were found). Considering the average prevalence of infection of $4.4 \%$ in RR and the 98 samples tested at Police Bay, the probability of having at least one positive rat is $98.7 \%$ according to the Poisson distribution. We can therefore reasonably state that the RR population in the south of Mahé (and its environment) is free of leptospires.

The distribution of leptospires, as found in these rats, could correspond to a specific carrying capacity of the species and/or be related to the environmental factors that determine Leptospira survival during the environmental phase. For the first hypothesis, more genetic studies would be required, but we can still see that in environments where prevalence is higher, it is high for both species. The second hypothesis seems more plausible, with some environments being more favorable to the maintenance and transmission of 
leptospires. Our geospatial analyses have determined a selection of important factors strongly correlated with an increasing Leptospira positivity in Rattus spp., including lower elevation in relation to a specific distance range to dense urban areas and a higher distance to forested areas, a proximity to surface water for $\mathrm{RN}$, a more fragmented landscape, and most of all, higher rainfall during the three months before trapping. Some of these factors are also related to each other and, together, reflect anthropogenic disturbances, peri-urban areas, low elevation and near-water environments. The influence of habitat fragmentation on Leptospira positivity in both Rattus spp. can possibly be explained by the increased availability of food, water and shelter presented by such landscapes, in which density-dependent pathogen transmission could occur. Habitat fragmentation has been shown to promote an increase in host rodent presence and in turn on their parasites [62]. In Seychelles, fragmentation and urbanization seem to favor the presence of RN and Leptospira, which also leads to RR becoming more contaminated in these environments.

Rainfall appears to be a major factor influencing the distribution and infection rates of Rattus spp. The accumulation of water following rainfall may help transmission, as it brings Leptospira-infected environments closer to animal hosts. The runoff of water towards the coastal areas also accounts for the concentration of leptospires at lower elevations. The nonlinear and lagged relationship between rainfall and human infection, as well as the role of floods, has been previously shown [63]. Our study is consistent with what is known of Leptospira infection of rats following rain [64]. However, the fact that it follows the same lagged relationship as in humans is interesting.

The multivariate modeling confirms the importance of fragmentation and rainfall variables, which are the most discriminating variables to differentiate between carrier and healthy rats. Nevertheless, we need to integrate the species variable with these environmental variables to obtain a predictive model of leptospires carriage. If the models had been based only on environmental variables, we could have considered extrapolating it spatially to the whole island to make a risk map.

Finally, it is important to note that a previous investigation comparing Leptospira genotypes in both human acute cases and rodents in Seychelles has shown that rats can be considered the source of human infection in only a third of acute cases [14]. Our study confirms this previous result, as there is a poor overlap between the distribution of infected rats and human acute cases (Figure 3). Nevertheless, more precise data on the places of residence and infection of human cases over several years would be needed to compare this study with human epidemiology. As leptospirosis is still of great medical importance in this country, it is important to determine the environmental conditions that contribute to its survival and the animal species that act as carriers or reservoirs, in order to implement targeted control actions. Then, it would be interesting to complete this study at a microscale with chemical measurements of the soils in these environments to see more precisely the parameters that contribute to the survival of leptospires. Urban planning could be used to mitigate rat abundance and maximize the efficiency of rodent control (for example, by limiting landscape fragmentation) with the aim of reducing human contact with pathogens like Leptospira [65]. In certain areas (e.g., La Misère village), control strategies to limit the highly negative impact of rats on the autochthonous fauna and flora of Seychelles [47] should be designed to also contribute to this goal, and both advantages should be promoted to resident communities.

\section{Conclusions}

A geospatial analysis of infected and noninfected rodent reservoirs allowed us to identify favorable environments for their presence. In the Seychelles, we showed the major importance of Rattus norvegicus in fragmented environments and confirmed the relationship with rainfall to explain leptospirosis carriage. This highlights that the use of remote sensing for landscape observation and rainfall measurement can help identify suitable environments to leptospires, which represent a risk for transmission to humans. 
This could help public health interventions strategies in the prevention and control of leptospirosis cases.

Author Contributions: Conceptualization, P.T., K.D., V.G.-C. and V.H.; methodology, V.H., C.R., G.R. and L.B.; data curation, L.B., E.L., Y.G., G.L.M., G.R., C.R., J.M. and V.H.; formal analysis, V.H., L.B., C.R. and S.J.; writing—original draft, V.H. and L.B.; writing—review and editing, all authors. All authors have read and agreed to the published version of the manuscript.

Funding: This study received funding from FEDER INTERREG V program through LEPTOI 32913 project. L.B. received a PhD scholarship (ARTS) from the French National Research Institute for Sustainable Development (IRD).

Institutional Review Board Statement: The study was conducted according to the guidelines of the Declaration of Helsinki, and approved by the Seychelles Bureau of Standards (ref. A0157) and the CYROI Institutional Animal Care and Use Committee (Comité d'Ethique du CYROI n ${ }^{\circ} 114$, IACUC certified by the French Ministry of Higher Education and Research).

Informed Consent Statement: Not applicable.

Data Availability Statement: The data presented in this study are openly available in DataSuds at https://doi.org/10.23708/HETOF3.

Acknowledgments: We would like to thank the Ministry of Health, the Ministry of Environment, the National Bureau of Statistics and the Seychelles Bureau of Standards of the Republic of Seychelles for providing data and the required permits. We also thank the Ministry of Habitat, Infrastructure and Land Transport and the Seychelles Meteorological Authority for providing additional geographic and meteorological information.

Conflicts of Interest: The authors declare no conflict of interest.

\section{References}

1. Ko, A.I.; Goarant, C.; Picardeau, M. Leptospira: The dawn of the molecular genetics era for an emerging zoonotic pathogen. Nat. Rev. Microbiol. 2009, 7, 736-747. [CrossRef]

2. $\quad$ Fouts, D.E.; Matthias, M.A.; Adhikarla, H.; Adler, B.; Amorim-Santos, L.; Berg, D.E.; Bulach, D.; Buschiazzo, A.; Chang, Y.-F.; Galloway, R.L.; et al. What Makes a Bacterial Species Pathogenic?: Comparative Genomic Analysis of the Genus Leptospira. PLoS Negl. Trop. Dis. 2016, 10, e0004403. [CrossRef]

3. Bharti, A.R.; Nally, J.E.; Ricaldi, J.N.; Matthias, M.A.; Diaz, M.M.; Lovett, M.A.; Levett, P.N.; Gilman, R.H.; Willig, M.R.; Gotuzzo, E.; et al. Leptospirosis: A zoonotic disease of global importance. Lancet Infect. Dis. 2003, 3, 757-771. [CrossRef]

4. Desvars, A.; Cardinale, E.; Michault, A. Animal leptospirosis in small tropical areas. Epidemiol. Infect. 2010, 139, 1-22. [CrossRef]

5. Costa, F.; Hagan, J.E.; Calcagno, J.; Kane, M.; Torgerson, P.; Martinez-Silveira, M.S.; Stein, C.; Abela-Ridder, B.; Ko, A.I. Global Morbidity and Mortality of Leptospirosis: A Systematic Review. PLoS Negl. Trop. Dis. 2015, 9, e0003898. [CrossRef] [PubMed]

6. Picardeau, M. Leptospirosis: Updating the Global Picture of an Emerging Neglected Disease. PLoS Negl. Trop. Dis. 2015, 9, e0004039. [CrossRef]

7. Durski, K.N.; Jancloes, M.; Chowdhary, T.; Bertherat, E. A Global, Multi-Disciplinary, Multi-Sectorial Initiative to Combat Leptospirosis: Global Leptospirosis Environmental Action Network (GLEAN). Int. J. Environ. Res. Public Health 2014, 11, 6000-6008. [CrossRef] [PubMed]

8. Mwachui, M.A.; Crump, L.; Hartskeerl, R.; Zinsstag, J.; Hattendorf, J. Environmental and Behavioural Determinants of Leptospirosis Transmission: A Systematic Review. PLoS Negl. Trop. Dis. 2015, 9, e0003843. [CrossRef]

9. Allan, K.J.; Biggs, H.M.; Halliday, J.E.B.; Kazwala, R.R.; Maro, V.P.; Cleaveland, S.; Crump, J.A. Epidemiology of Leptospirosis in Africa: A Systematic Review of a Neglected Zoonosis and a Paradigm for ‘One Health' in Africa. PLoS Negl. Trop. Dis. 2015, 9, e0003899. [CrossRef]

10. Hartskeerl, R.A.; Collares-Pereira, M.; Ellis, W.A. Emergence, control and re-emerging leptospirosis: Dynamics of infection in the changing world. Clin. Microbiol. Infect. 2011, 17, 494-501. [CrossRef]

11. Andre-Fontaine, G.; Aviat, F.; Thorin, C. Waterborne Leptospirosis: Survival and Preservation of the Virulence of Pathogenic Leptospira spp. in Fresh Water. Curr. Microbiol. 2015, 71, 136-142. [CrossRef]

12. Thibeaux, R.; Geroult, S.; Benezech, C.; Chabaud, S.; Soupé-Gilbert, M.-E.; Girault, D.; Bierque, E.; Goarant, C. Seeking the environmental source of Leptospirosis reveals durable bacterial viability in river soils. PLoS Negl. Trop. Dis. 2017, 11. [CrossRef]

13. Gonzalez-Astudillo, V.; Bustamante-Rengifo, J.A.; Bonilla, Á.; Lehmicke, A.J.J; Castillo, A.; Astudillo-Hernández, M. Synanthropic Cockroaches (Blattidae: Periplaneta spp.) Harbor Pathogenic Leptospira in Colombia. J. Med. Entomol. 2016, 53, 177-182. [CrossRef]

14. Biscornet, L.; Dellagi, K.; Pagès, F.; Bibi, J.; de Comarmond, J.; Mélade, J.; Govinden, G.; Tirant, M.; Gomard, Y.; Guernier, V.; et al. Human leptospirosis in Seychelles: A prospective study confirms the heavy burden of the disease but suggests that rats are not the main reservoir. PLoS Negl. Trop. Dis. 2017, 11, e0005831. [CrossRef] 
15. Herbreteau, V. When geography of health meets health ecology. In The Biogeography of Host-Parasite Interaction; Morand, S., Krasnov, B., Eds.; Oxford University Press: Oxford, NY, USA, 2010; pp. 247-265. ISBN 978-0-19-956135-3.

16. Soberon, J.; Peterson, A.T. Interpretation of Models of Fundamental Ecological Niches and Species' Distributional Areas. Biodivers. Inform. 2005, 2, 1-10. [CrossRef]

17. Lau, C.L.; Smythe, L.D.; Craig, S.B.; Weinstein, P. Climate change, flooding, urbanisation and leptospirosis: Fuelling the fire? Trans. R. Soc. Trop. Med. Hyg. 2010, 104, 631-638. [CrossRef]

18. Ledien, J.; Sorn, S.; Hem, S.; Huy, R.; Buchy, P.; Tarantola, A.; Cappelle, J. Assessing the performance of remotely-sensed flooding indicators and their potential contribution to early warning for leptospirosis in Cambodia. PLoS ONE 2017, 12, e0181044. [CrossRef]

19. Weinberger, D.; Baroux, N.; Grangeon, J.-P.; Ko, A.I.; Goarant, C. El Niño Southern Oscillation and Leptospirosis Outbreaks in New Caledonia. PLoS Negl. Trop. Dis. 2014, 8, e2798. [CrossRef]

20. Schneider, M.C.; Najera, P.; Pereira, M.M.; Machado, G.; dos Anjos, C.B.; Rodrigues, R.O.; Cavagni, G.M.; Muñoz-Zanzi, C.; Corbellini, L.G.; Leone, M.; et al. Leptospirosis in Rio Grande do Sul, Brazil: An Ecosystem Approach in the Animal-Human Interface. PLoS Negl. Trop. Dis. 2015, 9, e0004095. [CrossRef]

21. Hagan, J.E.; Moraga, P.; Costa, F.; Capian, N.; Ribeiro, G.S.; Wunder, E.A., Jr.; Felzemburgh, R.D.M.; Reis, R.B.; Nery, N.; Santana, F.S.; et al. Spatiotemporal Determinants of Urban Leptospirosis Transmission: Four-Year Prospective Cohort Study of Slum Residents in Brazil. PLoS Negl. Trop. Dis. 2016, 10, e0004275. [CrossRef]

22. Cosson, J.-F.; Picardeau, M.; Mielcarek, M.; Tatard, C.; Chaval, Y.; Suputtamongkol, Y.; Buchy, P.; Jittapalapong, S.; Herbreteau, V.; Morand, S. Epidemiology of Leptospira Transmitted by Rodents in Southeast Asia. PLoS Negl. Trop. Dis. 2014, 8, e2902. [CrossRef] [PubMed]

23. Della Rossa, P.; Tantrakarnapa, K.; Sutdan, D.; Kasetsinsombat, K.; Cosson, J.-F.; Supputamongkol, Y.; Chaisiri, K.; Tran, A.; Supputamongkol, S.; Binot, A.; et al. Environmental factors and public health policy associated with human and rodent infection by leptospirosis: A land cover-based study in Nan province, Thailand. Epidemiol. Infect. 2016, 144, 1550-1562. [CrossRef] [PubMed]

24. Catry, T.; Li, Z.; Roux, E.; Herbreteau, V.; Gurgel, H.; Mangeas, M.; Seyler, F.; Dessay, N. Wetlands and Malaria in the Amazon: Guidelines for the Use of Synthetic Aperture Radar Remote-Sensing. Int. J. Environ. Res. Public Health 2018, 15, 468. [CrossRef] [PubMed]

25. Suwanpakdee, S.; Kaewkungwal, J.; White, L.J.; Asensio, N.; Ratanakorn, P.; Singhasivanon, P.; Day, N.P.J.; Pan-Ngum, W. Spatio-temporal patterns of leptospirosis in Thailand: Is flooding a risk factor? Epidemiol. Infect. 2015, 143, 2106-2115. [CrossRef]

26. Rakwatin, P.; Sansena, T.; Marjang, N.; Rungsipanich, A. Using multi-temporal remote-sensing data to estimate 2011 flood area and volume over Chao Phraya River basin, Thailand. Remote Sens. Lett. 2013, 4, 243-250. [CrossRef]

27. Pinn, T.G. Leptospirosis in the Seychelles. Med. J. Aust. 1992, 156, 163-167. [CrossRef]

28. Yersin, C.; Bovet, P.; Mérien, F.; Wong, T.; Panowsky, J.; Perolat, P. Human leptospirosis in the Seychelles (Indian Ocean): A population-based study. Am. J. Trop. Med. Hyg. 1998, 59, 933-940. [CrossRef]

29. Russell, J.C.; Cole, N.C.; Zuël, N.; Rocamora, G. Introduced mammals on Western Indian Ocean islands. Glob. Ecol. Conserv. 2016, 6, 132-144. [CrossRef]

30. Dietrich, M.; Gomard, Y.; Lagadec, E.; Ramasindrazana, B.; Le Minter, G.; Guernier, V.; Benlali, A.; Rocamora, G.; Markotter, W.; Goodman, S.M.; et al. Biogeography of Leptospira in wild animal communities inhabiting the insular ecosystem of the western Indian Ocean islands and neighboring Africa. Emerg. Microbes Infect. 2018, 7, 1-12. [CrossRef]

31. Mills, J.N.; Childs, J.E.; Ksiazek, T.G.; Peters, C.J.; Velleca, W.M. Methods for Trapping and Sampling Small Mammals for Virologic Testing; U.S. Department of Health and Human Services-Centers for Disease Control and Prevention: Atlanta, GA, USA, 1995.

32. Aplin, K.P.; Brown, P.R.; Jacob, J.; Krebs, C.J.; Singleton, G.R. Field Methods for Rodent Studies in Asia and the Indo-Pacific; Monograph No.100; ACIAR: Canberra, Australia, 2003; ISBN 1-86320-393-1.

33. Herbreteau, V.; Jittapalapong, S.; Rerkamnuaychoke, W.; Chaval, Y.; Cosson, J.-F.; Morand, S. Protocols for Field and Laboratory Rodent Studies; Kasetsart University Press: Bangkok, Thailand, 2011.

34. Révillion, C.; Lagadec, E.; Le Minter, G.; Dessay, N.; Guernier, V.; Sand, A.; Tortosa, P.; Dellagi, K.; Herbreteau, V. Utilisation de la très haute résolution spatiale pour la caractérisation des habitats de rongeurs, vecteurs de zoonoses à la Réunion. Rev. Fr. Photogramm. Télédétect. 2015, 209, 65-71.

35. Révillion, C.; Attoumane, A.; Herbreteau, V. Homisland-IO: Homogeneous Land Use/Land Cover over the Small Islands of the Indian Ocean. Data 2019, 4, 82. [CrossRef]

36. Anderson, J.R.; Hardy, E.E.; Roach, J.T.; Witmer, R.E. A Land Use and Land Cover Classification System for Use with Remote Sensor Data; Geological Survey Professional Paper Series; U.S. Government Publishing Office: Washington, DC, USA, 1976.

37. Foody, G.M. Status of land cover classification accuracy assessment. Remote Sens. Environ. 2002, 80, 185-201. [CrossRef]

38. Morand, S.; Bordes, F.; Blasdell, K.; Pilosof, S.; Cornu, J.-F.; Chaisiri, K.; Chaval, Y.; Cosson, J.-F.; Claude, J.; Feyfant, T.; et al. Assessing the distribution of disease-bearing rodents in human-modified tropical landscapes. J. Appl. Ecol. 2015, 52, 784-794. [CrossRef]

39. R Core Team. R: A Language and Environment for Statistical Computing; R Foundation for Statistical Computing: Vienna, Austria, 2020.

40. Brotons, L.; Thuiller, W.; Araujo, M.B.; Hirzel, A.H. Presence-absence versus presence-only modelling methods for predicting bird habitat suitability. Ecography 2004, 27, 437-448. [CrossRef]

41. Chesson, P. Mechanisms of Maintenance of Species Diversity. Annu. Rev. Ecol. Syst. 2000, 31, 343-366. [CrossRef]

42. Russell, J.C.; Caut, S.; Anderson, S.H.; Lee, M. Invasive rat interactions and over-invasion on a coral atoll. Biol. Conserv. 2015, 185, 59-65. [CrossRef] 
43. Carver, S.; Mills, J.N.; Kuenzi, A.; Flietstra, T.; Douglass, R.J. Sampling frequency differentially influences interpretation of zoonotic pathogen and host dynamics: Sin Nombre virus and deer mice. Vector Borne Zoonotic Dis. 2010, 10, 575-583. [CrossRef]

44. Panti-May, J.A.; Carvalho-Pereira, T.S.A.; Serrano, S.; Pedra, G.G.; Taylor, J.; Pertile, A.C.; Minter, A.; Airam, V.; Carvalho, M.; Júnior, N.N.; et al. A Two-Year Ecological Study of Norway Rats (Rattus norvegicus) in a Brazilian Urban Slum. PLoS ONE 2016, 11, e0152511. [CrossRef]

45. Vadell, M.V.; Cavia, R.; Suárez, O.V. Abundance, age structure and reproductive patterns of Rattus norvegicus and Mus musculus in two areas of the city of Buenos Aires. Int. J. Pest. Manag. 2010, 56, 327-336. [CrossRef]

46. Harper, G.A.; Bunbury, N. Invasive rats on tropical islands: Their population biology and impacts on native species. Glob. Ecol. Conserv. 2015, 3, 607-627. [CrossRef]

47. Rocamora, G.; Henriette, E. Invasive Alien Species in Seychelles: Why and How to Eliminate Them? Identification and Management of Priority Species; Biotope, Muséum National d'Histoire Naturelle: Paris, France, 2015.

48. Hill, M.J.; Vel, T.; Shah, N.J. The morphology, distribution and conservation implications of introduced rats, Rattus spp. in the granitic Seychelles. Afr. J. Ecol. 2003, 41, 179-186. [CrossRef]

49. Herbreteau, V.; Bordes, F.; Jittapalapong, S.; Supputamongkol, Y.; Morand, S. Rodent-borne diseases in Thailand: Targeting rodent carriers and risky habitats. Infect. Ecol. Epidemiol. 2012, 2. [CrossRef] [PubMed]

50. Andersen-Ranberg, E.U.; Pipper, C.; Jensen, P.M. Global patterns of leptospira prevalence in vertebrate reservoir hosts. J. Wildl. Dis. 2016, 52, 468-477. [CrossRef]

51. Krøjgaard, L.H.; Villumsen, S.; Markussen, M.D.K.; Jensen, J.S.; Leirs, H.; Heiberg, A.-C. High prevalence of Leptospira spp. in sewer rats (Rattus norvegicus). Epidemiol. Infect. 2009, 137, 1586-1592. [CrossRef] [PubMed]

52. Costa, F.; Wunder, E.A.; De Oliveira, D.; Bisht, V.; Rodrigues, G.; Reis, M.G.; Ko, A.I.; Begon, M.; Childs, J.E. Patterns in Leptospira Shedding in Norway Rats (Rattus norvegicus) from Brazilian Slum Communities at High Risk of Disease Transmission. PLoS Negl. Trop. Dis. 2015, 9, e0003819. [CrossRef]

53. Muñoz-Zanzi, C.; Mason, M.; Encina, C.; Gonzalez, M.; Berg, S. Household Characteristics Associated with Rodent Presence and Leptospira Infection in Rural and Urban Communities from Southern Chile. Am. J. Trop. Med. Hyg. 2014, 90, 497-506. [CrossRef]

54. Van Der Geer, A.A.E. Changing invaders: Trends of gigantism in insular introduced rats. Environ. Conserv. 2018, 45, 203-211. [CrossRef]

55. Berdoy, M.; Drickamer, L.C. Comparative social organization and life history of Rattus and Mus. In Rodent Societies: An Ecological and Evolutionary Perspective; University of Chicago Press: Chicago, IL, USA, 2007; pp. 380-392.

56. Desvars-Larrive, A.; Baldi, M.; Walter, T.; Zink, R.; Walzer, C. Brown rats (Rattus norvegicus) in urban ecosystems: Are the constraints related to fieldwork a limit to their study? Urban Ecosyst. 2018, 21, 951-964. [CrossRef]

57. Guiry, E.; Buckley, M. Urban rats have less variable, higher protein diets. Proc. R. Soc. B Biol. Sci. 2018, 285, 20181441. [CrossRef]

58. Aplin, K.P.; Suzuki, H.; Chinen, A.A.; Chesser, R.T.; ten Have, J.; Donnellan, S.C.; Austin, J.; Frost, A.; Gonzalez, J.P.; Herbreteau, V.; et al. Multiple Geographic Origins of Commensalism and Complex Dispersal History of Black Rats. PLoS ONE 2011, 6, e26357. [CrossRef]

59. Feng, A.Y.T.; Himsworth, C.G. The secret life of the city rat: A review of the ecology of urban Norway and black rats (Rattus norvegicus and Rattus rattus). Urban Ecosyst. 2014, 17, 149-162. [CrossRef]

60. Byers, K.A.; Lee, M.J.; Patrick, D.M.; Himsworth, C.G. Rats About Town: A Systematic Review of Rat Movement in Urban Ecosystems. Front. Ecol. Evol. 2019, 7, 13. [CrossRef]

61. Cheke, A. The timing of arrival of humans and their commensal animals on Western Indian Ocean oceanic islands. Phelsuma 2010, 18, 38-69.

62. Bordes, F.; Morand, S.; Pilosof, S.; Claude, J.; Krasnov, B.R.; Cosson, J.-F.; Chaval, Y.; Ribas, A.; Chaisiri, K.; Blasdell, K.; et al. Habitat fragmentation alters the properties of a host-parasite network: Rodents and their helminths in South-East Asia. J. Anim. Ecol. 2015, 84, 1253-1263. [CrossRef] [PubMed]

63. Matsushita, N.; Ng, C.F.S.; Kim, Y.; Suzuki, M.; Saito, N.; Ariyoshi, K.; Salva, E.P.; Dimaano, E.M.; Villarama, J.B.; Go, W.S.; et al. The non-linear and lagged short-term relationship between rainfall and leptospirosis and the intermediate role of floods in the Philippines. PLoS Negl. Trop. Dis. 2018, 12, e0006331. [CrossRef] [PubMed]

64. Ivanova, S.; Herbreteau, V.; Blasdell, K.; Chaval, Y.; Buchy, P.; Guillard, B.; Morand, S. Leptospira and Rodents in Cambodia: Environmental Determinants of Infection. Am. J. Trop. Med. Hyg. 2012, 86, 1032-1038. [CrossRef]

65. Cavia, R.; Cueto, G.R.; Suárez, O.V. Changes in rodent communities according to the landscape structure in an urban ecosystem. Landsc. Urban Plan. 2009, 90, 11-19. [CrossRef] 